\title{
Whole gene analysis of a genotype G29P[6] human rotavirus strain identified in Central African Republic
}

\author{
Virginie Banga-Mingo ${ }^{1 \dagger}$, Mathew D. Esona ${ }^{2 *}+\mathbb{C}$, Naga S. Betrapally², Rashi Gautam², Jose Jaimes ${ }^{2}$, Eric Katz ${ }^{2}$, \\ Diane Waku-Kouomou' ${ }^{2}$ Michael D. Bowen ${ }^{2+}$ and Ionela Gouandjika-Vasilache ${ }^{1 \dagger}$
}

\begin{abstract}
Objective: Rotavirus A (RVA) remains the main causative agent of gastroenteritis in young children and the young of many mammalian and avian species. In this study we describe a RVA strain detected from a 6-month-old child from Central African Republic (CAR).

Results: We report the 11 open reading frame sequences of a G29-P[6]-I2-R2-C2-M2-A2-N2-T2-E2-H2 rotavirus strain, RVA/Human-wt/CAR/CAR91/2014/G29P[6]. Nine genes (VP1-VP3, VP6, NSP1-NSP5) shared 90-100\% sequence similarities with genogroup 2 rotaviruses. Phylogenetically, backbone genes, except for VP3 and NSP4 genes, were linked with cognate gene sequences of human DS-1-like genogroup 2, hence their genetic origin. The VP3 and NSP4 genes, clustered genetically with both human and animal strains, an indication genetic reassortment human and animal RVA strains has taken place. The VP7 gene shared nucleotide (93-94\%) and amino acid (95.5-96.7\%) identities with Kenyan and Belgian human G29 strains, as well as to buffalo G29 strain from South Africa, while the VP4 gene most closely resembled P[6]-lineage I strains from Africa and Bangladesh (97\%).
\end{abstract}

Keywords: RVA, Whole genome analysis, Central African Republic

\section{Introduction}

Rotavirus A (RVA) is a major cause of diarrhea in infants and young animals worldwide [1]. The RVA genomic classification nomenclature is based on all 11 segments of double-stranded RNA (dsRNA) that encode for six structural proteins (VP1-VP4, VP6, and VP7) and five or six non-structural proteins (NSP1-NSP5/6) [1]. The genotypes of the VP7,VP4,VP6,VP1,VP2,VP3, NSP1, NSP2, NSP3, NSP4, and NSP5 genes are designated

\footnotetext{
*Correspondence: mdi4@cdc.gov

'Virginie Banga-Mingo and Mathew D. Esona contributed equally to this article

${ }^{\dagger}$ Michael D. Bowen and lonela Gouandjika-Vasilache contributed equally to this article

${ }^{2}$ Viral Gastroenteritis Branch, Division of Viral Diseases, NCIRD, CDC, 1600

Clifton Road, NE, Atlanta, GA 30329, USA

Full list of author information is available at the end of the article
}

$\mathrm{G} x-\mathrm{P}[x]-\mathrm{I} x-\mathrm{R} x-\mathrm{C} x-\mathrm{M} x-\mathrm{A} x-\mathrm{N} x-\mathrm{T} x-\mathrm{E} x-\mathrm{H} x$, where $x$ indicates the genotype number [2]. For a majority of human RVA strains, disparity in the backbone genes can be differentiated by three genotype patterns, the Wa-like genogroup 1 (I1-R1-C1-M1-A1-N1-T1-E1-H1), the DS-1-like genogroup 2 (I2-R2-C2-M2-A2-N2-T2-E2-H2), and the AU-1-like genogroup 3 (I3-R3-C3-M3-A3-N3-T3E3-H3) that are believed to have originated from porcine, bovine, and feline RVAs, respectively [3]. To date, 36 G, 51 P, 26 I, 22 R, 20 C, 20M, 31 A, 22N, 22T, $27 \mathrm{E}$ and $22 \mathrm{H}$ genotypes have been identified in human and non-human hosts and classified based on differences in the nucleotide sequence identities of each encoding gene segment, respectively [3]; http://rega.kuleuven.be/cev/ viralmetagenomics/virus-classification. This classification system has accelerated the comparison of RVA genotypes and increased our understanding of the genetic

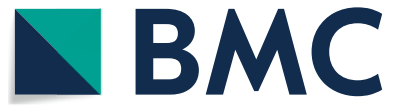

(c) The Author(s) 2021. This article is licensed under a Creative Commons Attribution 4.0 International License, which permits use, sharing adaptation, distribution and reproduction in any medium or format, as long as you give appropriate credit to the original author(s) and the source, provide a link to the Creative Commons licence, and indicate if changes were made. The images or other third party material in this article are included in the article's Creative Commons licence, unless indicated otherwise in a credit line to the material. If material is not included in the article's Creative Commons licence and your intended use is not permitted by statutory regulation or exceeds the permitted use, you will need to obtain permission directly from the copyright holder. To view a copy of this licence, visit http://creativeco mmons.org/licenses/by/4.0/. The Creative Commons Public Domain Dedication waiver (http://creativecommons.org/publicdomain/ zero/1.0/) applies to the data made available in this article, unless otherwise stated in a credit line to the data. 
diversity of RVA. Interspecies transmission and genetic reassortment between human and animal RVA have been frequently described, and pigs and cattle are considered the major reservoirs for the genetic and antigenic diversity of human RVA strains.

RVA genotype G29 is rare and has been reported only twice in humans and once in animal previously. The first human strain RVA/Human-wt/BEL/BEF06018/2014/ G29P[41] with genetic constellation of G29P[41]-I2R2-C2-M2-A3-N2-T6-E2-H3 was detected in Belgium in 2013 [4]. The second human strain RVA/Human-wt/ KEN/0279/2010/G29P[X] was detected in Kenya in 2010 and only the VP7 gene of this strain has been sequenced [5]. Finally, a single animal strain, RVA/Buffalo-wt/ ZAF/4426/2002/G29P[14] with genetic constellation of G29-P[14]-I2-R2-C2-M2-A11-N2-T6-E2-H3 has been detected in a South African buffalo [6]. Here we report the full gene molecular characterization of a novel human G29P[6] RVA strain from the Central African Republic (CAR).

\section{Main text \\ Methods \\ Patient and sample collection}

In 2014, a 6-month-old child was hospitalized for acute diarrhea with fever and vomiting at the Complexe Pédiatrique, Bangui (CPB), CAR. The patient had no record of exposure to animals. Diarrheic stool specimen was collected and tested at surveillance site laboratory for RVA antigen by using the Rotaclone EIA kit (Premier Rotaclone $^{\mathrm{TM}}$, Meridian Diagnostics, Cincinnati, OH, USA), according to the manufacturer's instructions. RVApositive stool specimen was shipped on ice packs to the Centers for Disease Control and Prevention (CDC) for genotyping and sequencing analyses.

\section{RVA dsRNA extraction, RT-PCR, sequencing and genotype assignment}

RNA was extracted from stool using the QIAamp Viral RNA mini kit according to the manufacturer's instructions (Qiagen, Valencia, CA, USA). The sequencing templates were prepared using sequence independent whole-genome reverse transcription-PCR (RT-PCR) amplification [7] with slight modifications. The amplified cDNA amplicons were sequenced using the Illumina MiSeq reagent kit v.2, 500 cycles and the standard $250 \mathrm{bp}$ paired-end reads method. Illumina sequence reads were analyzed using CLC Genomics Workbench 11.0 (http:// www.clcbio.com/products/clc-genomics-workbench/) incorporating a combination of de novo- and referenceguided assemblies to generate contigs and consensus sequences to obtain the complete open reading frame (ORF) sequences of strain CAR91/2014. Genotypes were determined using RotaC 2.0 (http://rotac.regatools.be/) [8].

\section{Phylogenetic and genetic analyses}

For each gene, multiple alignments were made by using the MUSCLE algorithm implemented in MEGA6 software [9], http://www.megasoftware.net/). Once aligned, the DNA Model Test program implemented in MEGA version 6 was used to identify the optimal evolutionary models that best fit the sequence datasets. Using Corrected Akaike Information Criterion (AICc), the following models were found to best fit the sequence data for the indicated genes: GTR + G + I (VP1, VP2, VP3, VP4, VP6, VP7, NSP1, NSP2, and NSP3), GTR + G (NSP4), and $\mathrm{HKY}+\mathrm{G}$ (NSP5). With these models, maximumlikelihood trees were constructed using MEGA 6 with 1000 bootstrap replicates to estimate branch support. Nucleotide and amino acid distance matrices were prepared using the $p$-distance algorithm of MEGA 6 software [9].

\section{Results}

For RVA strain RVA/Human-wt/CAR/CAR91/2014/ G29P[6] (henceforth called CAR91/2014), the length of the open reading frames (ORF) for gene segments 1-11 was 3265, 2640, 2508, 2328, 1461, 1194, 933, 954, 978, 494, and $603 \mathrm{bp}$, respectively and the complete genotype constellation was G29-P[6]-I2-R2-C2-M2-A2-N2T2-E2-H2. The complete ORFs for all 11 genes of strain CAR91/2014 sequences were deposited in GenBank under accession numbers MT163234 to MT163244 for VP7, VP4, VP6, VP1, VP2, VP3, NSP1, NSP2, NSP3, NSP4, and NSP5, respectively.

\section{Phylogenetic analyses}

Phylogenetic analyses of the eleven gene segments revealed that the VP7 gene of strain CAR91/2014 occupied a basal position in the sub-lineage with two human strains, RVA/Human-wt/BEL/BEF06018/2014/ G29P[41] detected in Belgium and RVA/Human-wt/ KEN/0279/2010/G29P[X] detected in Kenya, and a single buffalo strain RVA/Buffalo-wt/ZAF/4426/2002/ G29P[14] detected in South Africa (Fig. 1A). Nucleotide distance matrices show that the VP7 gene of strain CAR91/2014 shared a moderately high nucleotide (amino acid) identities of 93-94.9\% (95.5-96.7\%) (data not shown) to cognate sequence of strains RVA/ Human-wt/BEL/BEF06018/2014/G29P[41], RVA/ Human-wt/KEN/0279/2010/G29P[X] and RVA/Buffalowt/ZAF/4426/2002/G29P[14]. The VP4 gene of strain CAR91/2014 clustered in a distinct sub-lineage with African and European human P[6] strains within lineage I of the P[6] genotype (Fig. 1B). Like with the VP7 gene, 

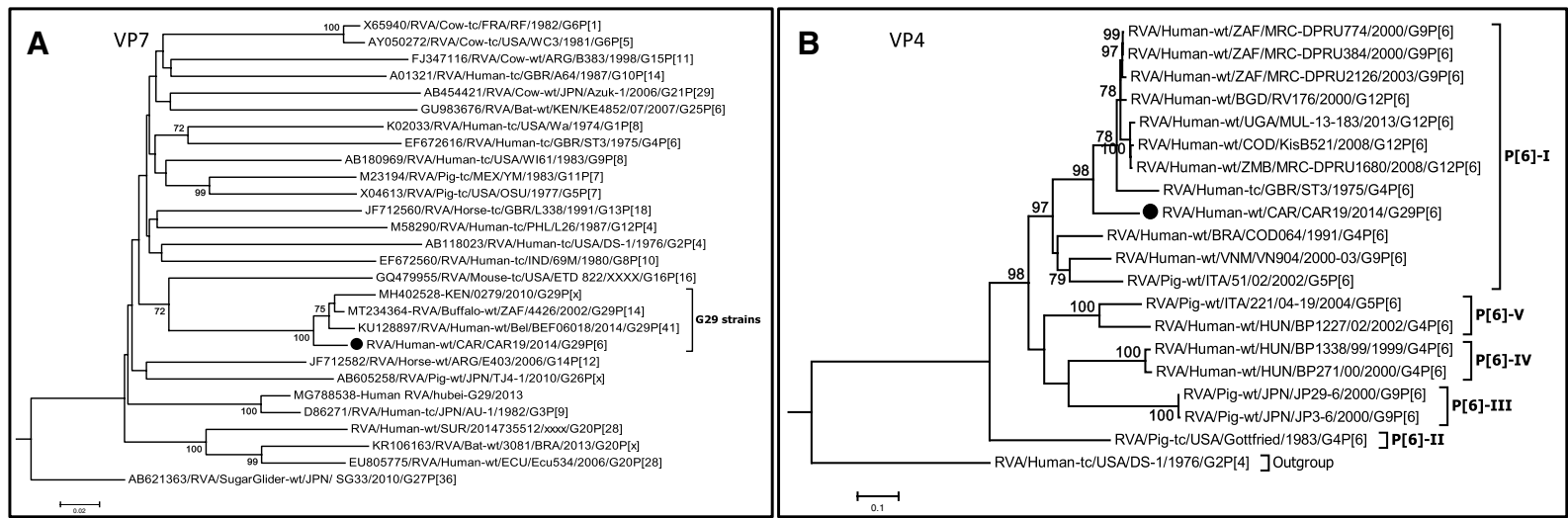

Fig. 1 A, B Phylograms indicating genetic relationships of complete nucleotide sequences of $\mathbf{A} \vee P 7$, and $\mathbf{B} \vee P 4$ of the study strain RVA/Human-wt/ CAR19/2014/G12P[6] from Central African Republic (indicated with a black circle) with representatives of known human and animal rotavirus genotypes. Bootstrap values $>70 \%$ are indicated at each branch node. Scale bars indicate the number of nucleotide substitutions per site

strain CAR91/2014 occupied a basal position within the sub-lineage. The VP4 gene of strain CAR/91/2014 was most similar (nucleotide $97 \%$, amino acid $98 \%$ ) to human G9-associated P[6] genes from South Africa and G12-associated P[6] genes from Bangladesh, Zambia, the Democratic Republic of Congo and Uganda (96-97\%), all of which belong to previously published $\mathrm{P}[6]$-lineage I [10]. With the exceptions of genes VP3 and NSP4, the remaining genes, VP1, VP2, VP6, NSP1, NSP2, NSP3, and NSP5 cluster closely with almost exclusively human genogroup 2 strains belonging to the $\mathrm{R} 2, \mathrm{C} 2, \mathrm{I} 2, \mathrm{~A} 2, \mathrm{~N} 2$, $\mathrm{T} 2$, and $\mathrm{H} 2$ genotypes, respectively (Fig. $2 \mathrm{~A}-\mathrm{I}$ ). The only closely related non-human strain sequences were the VP3 and NSP4 genes of ovine, buffalo and cow RVA strains RVA/Sheep-tc/ESP/OVR762/2002/G8P[14], RVA/Buffalo-wt/ZAF/4426/2002/G29P[14] and RVA/Cow-tc/ VEN/BRV003/1990/G6P[1]. However, the VP1, VP2, VP3, VP6, NSP1, NSP2, NSP3, NSP4 and NSP5 gene segments of strain CAR91/2014 shared greatest nucleotide (90-100\%) and amino acid (93-100\%) identities with
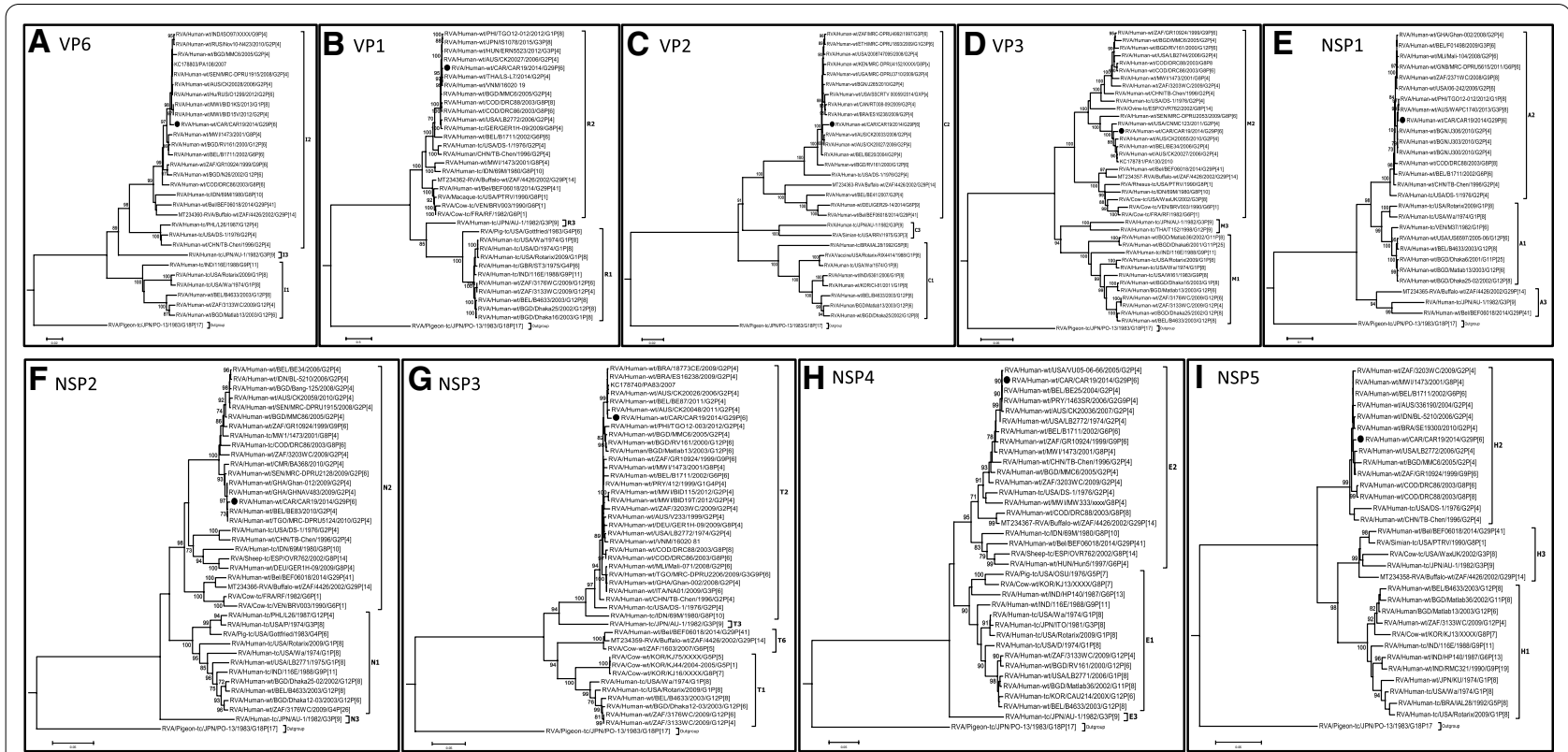

Fig. 2 A-I Phylograms indicating genetic relationships of complete nucleotide sequences of $\mathbf{A} \vee P 6, \mathbf{B} \vee P 1, \mathbf{C} V P 2, \mathbf{D} \vee P 3$, E NSP1, F NSP2, G NSP3, H NSP4 and I NSP5 of the study strain RVA/Human-wt/CAR19/2014/G12P[6] from Central African Republic (indicated with a black circle) with representatives of known human and animal rotavirus genotypes. Bootstrap values $>70 \%$ are indicated at each branch node. Scale bars indicate the number of nucleotide substitutions per site 
DS-1-like strains belonging to R2, C2, M2, I2, A2, N2, T2, $\mathrm{E} 2$ and $\mathrm{H} 2$ genotypes (data not shown).

\section{Discussion}

Here we present the sequence of strain CAR91/2014 which represents the fourth report of the G29 genotype and the first complete sequence for a G29P [6] RVA strain combination detected in humans. A unique feature of this CAR91/2014 strain is that the genes that constitute the genetic backbone belong exclusively to DS-1-like genogroup 2 of human origin, while those of the other human (RVA/Human-wt/BEL/BEF06018/2014/G29P[41]) and animal (RVA/Buffalo-wt/ZAF/4426/2002/G29P[14]) [6] G29 strains with complete sequences displayed the backbone I2-R2-C2-M2-A11-N2-T6-E2-H3,typical of artiodactyl RVA strains. Phylogenetically, the VP7 gene of the strain CAR91/2014 occupied the basal position of the G29 strains, suggesting that the CAR91/2014 might be the ancestral origin of all the G29 genotype that have been detected so far. Analysis of the genetic backbone of the CAR91/2014 strain shows that all the genes, with the exception of the VP3 and NSP4, appears to be human RVA and are phylogenetically linked to human DS-1-like genogroup 2 G9P[6], G12P[6], equine-like G3P [8], reassortant G1P[8] and G3P [4] strains from Australia, Uganda, Brazil, South Africa, Philippines, Thailand, Japan and Hungary. Phylogenetically, the VP3 and NSP4 genes of strain CAR91/2014 clustered together with both human and animal RVA strains, suggesting that the VP3 and NSP4 genes of ovine, buffalo and bovine strains might have originated from a genetic reassortment between human and animal strains. Unfortunately, the complete genome of the Kenyan G29 strain RVA/ Human-wt/KEN/0279/2010/G29P[X] was not available for comparison. In a nutshell, the closeness of the genetic backbone of strain CAR91/2014 to those of several DS1-like strains including reassortant G1P [8] and G3P[8] is an indication that any of these strains might have donated these genes to the CAR91/2014 strain.

Analysis of RVA complete-ORF sequences from all 11 genes provides valuable data to better understand the contemporary diversity among RVA strain and helps to expand our knowledge of the genetic diversity and origin of uncommon RVA genotypes such as CAR91/2014.

\section{Limitations}

This manuscript describe characterization of a single G29P[6] strain and there might be others in circulation in Central African Republic. Also, rotavirus vaccine has not been introduced in Central African Republic, hence no post vaccine data is included in this study.
Abbreviations

RVA: Rotavirus group A; CAR: Central African Republic; ORF: Open reading frame; EIA: Enzyme linked Immunosorbent Assay; RT-PCR: Reverse Transcription-Polymerase Chain Reaction.

\section{Acknowledgements}

We thank the staff of the Viral Gastroenteritis Branch at the Centers for Disease Control and Prevention and those in Institut Pasteur, Bangui, Central African Republic, for invaluable assistance. We also appreciate the contribution of the sentinel site staff, Complexe Pédiatrique de Bangui, who performed patient enrollment and stool collection. This study was supported by the Centers for Disease Control and Prevention and Institut Pasteur de Bangui.

\section{Disclaimer}

The findings and conclusions in this report are those of the author(s) and do not necessarily represent the official position of the Centers for Disease Control and Prevention. Names of specific vendors, manufacturers, or products are included for public health and informational purposes; inclusion does not imply endorsement of the vendors, manufacturers, or products by the Centers for Disease Control and Prevention or the US Department of Health and Human Services.

\section{Authors' contributions}

All authors read and approved the manuscript before submission. VBM and IGV were involved in samples collection process, MDE, RG, JJ, EK, BN and MDB performed the whole genome sequence. MDE, VBM, RG, IGV, JJ, EK, DWK, MDB contributed in data analysis and writing of the first draft of the article. All authors read and approved the final manuscript.

\section{Funding}

The authors have no funding to disclose. Funding for whole genome sequencing of this specimen was provided by the CDC.

\section{Availability of data and materials}

The datasets used and/or analyzed during the current study are available from the corresponding author on reasonable request.

\section{Declarations}

\section{Ethics approval and consent to participate}

Ethical and administrative permissions for this study were obtained from the "Comité d'Ethique et scientifique de la Faculté de Science de la Santé de I'Université de Bangui" on the July 18, 2020. Stool sample was taken after written informed consent from parents or guardians of child.

\section{Consent for publication}

Not applicable.

\section{Competing interests}

The authors declare that they have no competing interests.

\section{Author details}

${ }^{1}$ Laboratoire Des Virus Entériques/Rougeole, Institut Pasteur de Bangui, Ave de L'Indépendance, BP 923, Bangui, Central African Republic. ${ }^{2}$ Viral Gastroenteritis Branch, Division of Viral Diseases, NCIRD, CDC, 1600 Clifton Road, NE, Atlanta, GA 30329, USA.

Received: 9 January 2021 Accepted: 25 May 2021

Published online: 31 May 2021

\section{References}

1. Estes MKGH. Rotaviruses. In: Knipe DM, Howley PM, Cohen Jl, Griffin DE, Lamb RA, Martin MA, editors. Fields virology 2013, vol. 2. 6th ed. Philadelphia: Wolters Kluwer/Lippincott, Williams and Wilkins; 2013. p. 1347-401.

2. Matthijnssens J, Ciarlet M, Rahman M, Attoui H, Banyai K, Estes MK, et al. Recommendations for the classification of group A rotaviruses using all 11 genomic RNA segments. Arch Virol. 2008;153(8):1621-9. 
3. Matthijnssens J, Ciarlet M, McDonald SM, Attoui H, Banyai K, Brister JR, et al. Uniformity of rotavirus strain nomenclature proposed by the Rotavirus Classification Working Group (RCWG). Arch Virol. 2011;156(8):1397-413.

4. Heylen E ZM VT, Yinda CK. Human group A rotavirus strain shows new G- and and P-genotype and an animal genetic backbone. https://www. ncbi.nlm.nih.gov/nuccore/?term=rotavirus+strain+BEF06018. Accessed 20 Nov 2020.

5. Owor BE MM, Njeru RW, Mugo R, Nokes JD, Agoti CN. Molecular characterization of rotavirus group A strains circulating prior to vaccine introduction in rural coastal Kenya, 2002-2014. https://www.ncbi.nlm.nih. gov/nuccore/MH402528. Accessed 20 Nov 2020.

6. Strydom A, Donato C, Peenze I, Potgieter AC, Seheri M, O'Neill HG. Genetic characterisation of novel G29P[14] and G10P[11] rotavirus strains from African buffalo. Infect Genet Evol. 2020;85:104463.

7. Potgieter AC, Page NA, Liebenberg J, Wright IM, Landt O, van Dijk AA. Improved strategies for sequence-independent amplification and sequencing of viral double-stranded RNA genomes. J Gen Virol. 2009;90(Pt 6):1423-32.

8. Maes P, Matthijnssens J, Rahman M, Van Ranst M. RotaC: a web-based tool for the complete genome classification of group A rotaviruses. BMC Microbiol. 2009:9:238.

9. Tamura K, Stecher G, Peterson D, Filipski A, Kumar S. MEGA6: molecular evolutionary genetics analysis version 6.0. Mol Biol Evol. 2013;30(12):2725-9.

10. Stupka JA, Carvalho P, Amarilla AA, Massana M, Parra Gl, Argentinean National Surveillance Network for D. National Rotavirus Surveillance in Argentina: high incidence of G9P[8] strains and detection of G4P[6] strains with porcine characteristics. Infect Genet Evol. 2009;9(6):1225-31.

\section{Publisher's Note}

Springer Nature remains neutral with regard to jurisdictional claims in published maps and institutional affiliations.
Ready to submit your research? Choose BMC and benefit from:

- fast, convenient online submission

- thorough peer review by experienced researchers in your field

- rapid publication on acceptance

- support for research data, including large and complex data types

- gold Open Access which fosters wider collaboration and increased citations

- maximum visibility for your research: over $100 \mathrm{M}$ website views per year

At BMC, research is always in progress.

Learn more biomedcentral.com/submissions 